Article

\title{
Effect of the Content of Micro-Active Copper Tailing on the Strength and Pore Structure of Cementitious Materials
}

\author{
Liming Zhang ${ }^{1,2, *}$, Songbai Liu ${ }^{1}$ and Dongsheng Song ${ }^{1}$ \\ 1 Jiang Xi Buidings Materials Scientific Research \& Design Institute, Nanchang 330001, China; \\ Lsb8811@126.com (S.L.); Sds1791@126.com (D.S.) \\ 2 Department of Civil Engineering, Tsinghua University, Beijing 10084, China \\ * Correspondence: zlmnuaa@126.com; Tel.: +86-15797714900
}

Received: 5 May 2019; Accepted: 5 June 2019; Published: 9 June 2019

check for updates

\begin{abstract}
This study investigates the effect of micr-oaggregate filling with copper tailing on the pore structure of cement paste containing copper tailing (CPCT). The particle size of the CPCT and the pore structure of CPCT were analyzed by laser particle size analysis and mercury instruction porosimetry (MIP). Results showed that at the early stage of curing time, with increasing copper tailing content, the compressive strength of cement mortar with copper tailing (CMCT) was lower, and the porosity and pore diameter of CPCT were higher and greater; with the extension of curing age, when the content of copper tailing was less than $30 \%$, the compressive strength of CMCT and the porosity of CPCT changed slightly with the increase of the content of copper tailing. However, the maximum hole diameter of CPCT decreased gradually (a curing age between $7 \mathrm{~d}$ and $365 \mathrm{~d}$ under standard conditions). Scanning electron microscopy analysis showed that the early stage of cement hydration in the CPCT, the copper tailing did not fill the pores in CPCT well, while in the later stage of cement hydration, the microaggregates of copper tailing filled the pores well and closely combined with the surrounding hydration products. In the later stage of cement hydration, the microaggregate filling of copper tailing was primarily responsible for the strength increase of the CMCT.
\end{abstract}

Keywords: copper tailing; pore structure; microaggregate filling; compressive strength; particle size distribution

\section{Introduction}

The inventory of copper tailings in Jiangxi (Figure 1) is 496.17 million tons [1], with an annual increase of 44 million tons-the highest in Asia. The annual utilization rate is only 1\% [2]. A large number of non-exploitable tailing dam piles exist in the tailing dam, which has emerged as a significant potential safety hazard for the local ecological environment, and hence, urgently needs resource utilization [3]. Domestic and international experts [4-8] have focused on the preparation of concrete as a mineral admixture and studied its performance. They found that when the content of copper tailing slag is $5 \%$ of the cementing material, the performance of concrete can be improved, but beyond this content, the performance is deteriorated. Such a low content limits the large-scale application of copper tailing as mineral admixture in cement concrete, so it was urgent to find ways to improve the content of copper tailing in cement. Research showed that the pore structure has a significant impact on the mechanical properties and carbonation resistance [9], chloride ion erosion resistance [10-13], and other durability properties of cement concrete [14-19]. However, there is little research on the microscopic mechanism, especially on the pore structure of cement mortar with copper tailing (CMCT). Studying the pore structure is of great significance to understand the relationship between the performance and microstructure of CMCT. 
Hence, in this study, a ball mill was used to grind copper tailing to obtain a specific surface area of $591 \mathrm{~m}^{2} / \mathrm{kg}$; X-ray Computed Tomography Imaging (X-ct) was used to study the compressive strength of CMCT and pore structure of cement paste containing copper tailing (CPCT) of different ages under standard curing conditions, and scanning electron microscopy (SEM) was used to conduct auxiliary research to explore the influence of microaggregate filling of copper tailing on the pore structure of $\mathrm{CPCT}$, and thereby reveal the micromechanism of cement hydration of copper tailing.

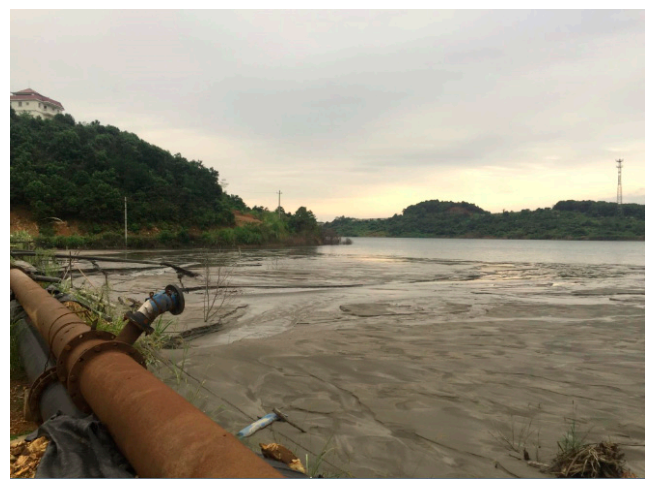

(a) Reservoir of copper tailings;

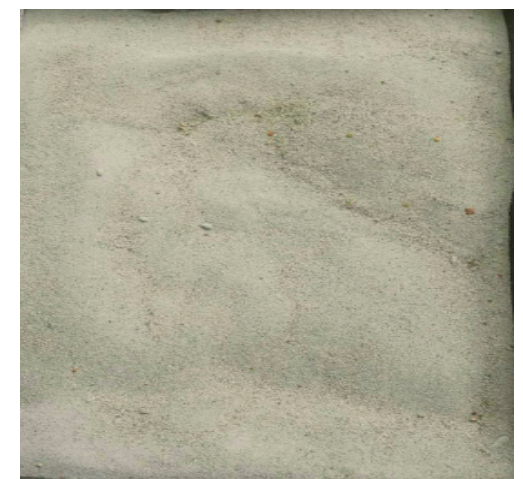

(b) Waste copper tailings

Figure 1. Copper tailings in Jiangxi Province.

\section{Materials and Methods}

\subsection{Raw Materials}

Copper tailing were procured from a copper mine in Ruichang City, Jiangxi Province, with the main chemical composition (Table 1) of $\mathrm{SiO}_{2}, \mathrm{Al}_{2} \mathrm{O}_{3}$, and $\mathrm{CaO}$ and trace amounts of $\mathrm{Fe}_{2} \mathrm{O}_{3}$ and $\mathrm{MgO}$. After grinding for $45 \mathrm{~min}$ with a special ball mill (Tencan Powder Changsha, Hunnan provice, China), the specific surface area of the copper tailing was $591 \mathrm{~m}^{2} / \mathrm{kg}$. The particle size distribution was determined by laser particle size analysis, as shown in Figure 2a,b. The chemical composition and particle size distribution of Jiangxi Conch 42.5 Ordinary Portland cement are shown in Table 1 and Figure 2a,b. The sand was standard sand and the particle size distribution of it is shown in Figure 2a,b. The water is tap water.

Table 1. Chemical composition of cementitious material.

\begin{tabular}{cccccccc}
\hline Binder Material Type & $\mathrm{SiO}_{2}$ & $\mathrm{Al}_{2} \mathrm{O}_{3}$ & $\mathrm{Fe}_{2} \mathrm{O}_{3}$ & $\mathrm{CaO}$ & $\mathrm{MgO}$ & $\mathrm{SO}_{3}$ & Loss \\
\hline Cement & 26.5 & 6.4 & 3.3 & 55.7 & 1.7 & 2.0 & 5.3 \\
\hline Copper tailing slag & 38.5 & 6.6 & 15.8 & 32.7 & 2.8 & 3.2 & 0.4 \\
\hline
\end{tabular}

Figure 2 shows the particle size distribution of the raw materials. Figure 2a shows that the mean particle size of copper tailing admixture after grinding for $45 \mathrm{~min}$ was around $5.6 \mu \mathrm{m}$ with $44 \%$ of particles passing, and the particle size range was $0-48.1 \mu \mathrm{m}$; the mean particle size of cement was around $17.0 \mu \mathrm{m}$ with $47 \%$, and the particle size range of cement was $0-100 \mu \mathrm{m}$; the mean particle size of standard sand was $500 \mu \mathrm{m}$ with $58 \%$, and the particle size range of standard sand was $80-2000 \mu \mathrm{m}$. The mean particle size of copper tailing was 0.33 and 0.01 times that of cement and standard sand, respectively. The maximum particle size of copper tailing was 0.48 times and 0.02 times that of cement and standard sand, respectively. Therefore, copper tailing can be filled in the pores of ordinary Portland cement [20-23]. 


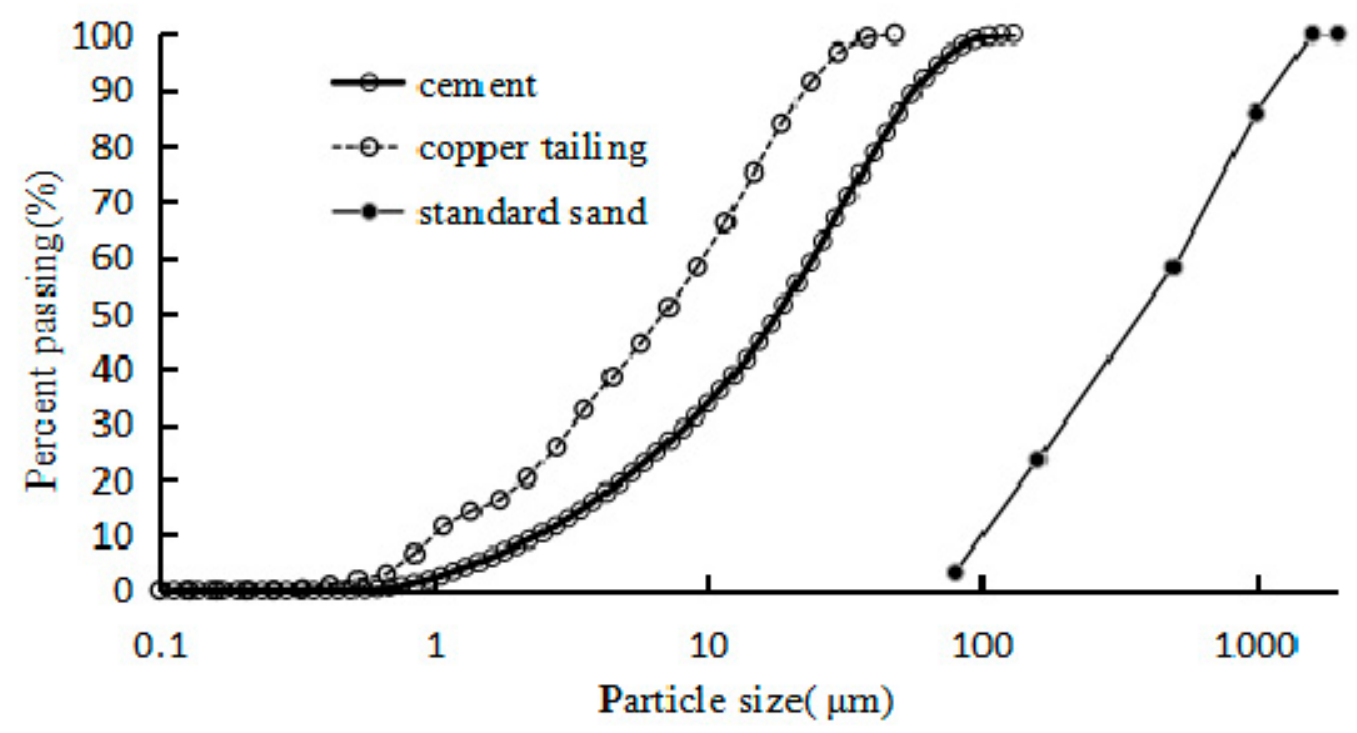

(a) Cumulative particle size distribution

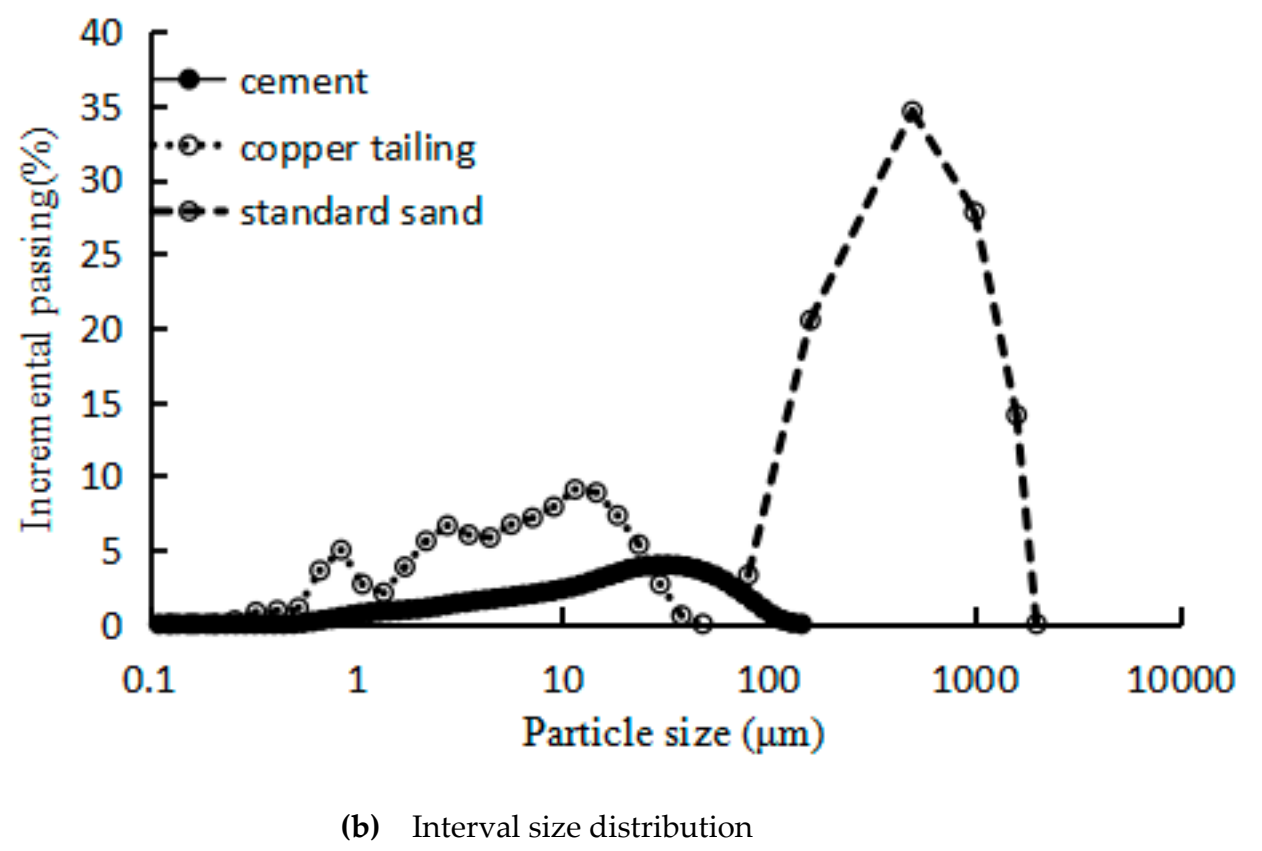

Figure 2. Particle size distribution of raw materials. (a) Cumulative particle size distribution; (b) Interval size distribution.

\subsection{Production of Test Pieces}

The cement mortar mix proportion and performance of the specimens is shown in Table 2. The setting time of cement mortar was not affected by the addition of copper tailing, and the fluidity of cement mortar with copper tailing was greater than $195 \mathrm{~mm}$, thereby meeting the requirements of the standard (GB/T1596-2017) [24]. Cement mortar specimens with size $70.7 \mathrm{~mm} \times 70.7 \mathrm{~mm} \times 70.7 \mathrm{~mm}$ were subjected to strength testing. Microstructure analysis was conducted with cement pastes of size $5 \mathrm{~mm} \times 5 \mathrm{~mm} \times 5 \mathrm{~mm}$. Twenty four hours after releasing from the mold, the specimens were cured in a standard environment $\left(20^{\circ} \mathrm{C}\right.$, humidity $95 \%$ or higher) for $6 \mathrm{~d}, 27 \mathrm{~d}, 89 \mathrm{~d}, 179 \mathrm{~d}$, and $364 \mathrm{~d}$, and were dried to a constant weight after the test. Then the cement mortar was tested for its mechanical 
intensity, micro-structure tests were conducted on the termination of hydration in anhydrous ethanol. The mixing of copper tailing did not affect the working performance of the cement mortar, as can be seen in Table 2.

Table 2. Cement mortar mix proportion and workable performance.

\begin{tabular}{cccccccc}
\hline Sample & Cement/g & $\begin{array}{c}\text { Copper } \\
\text { Tailing/s }\end{array}$ & Sand/g & Water/g & $\begin{array}{c}\text { Initial Setting } \\
\text { Time/min }\end{array}$ & $\begin{array}{c}\text { Final Setting } \\
\text { Time/min }\end{array}$ & Fluidity/mm \\
\hline CT0 & 450 & 0 & 1350 & 225 & 170 & 215 & 220 \\
\hline CT10 & 405 & 45 & 1350 & 225 & 170 & 215 & 225 \\
\hline CT20 & 360 & 90 & 1350 & 225 & 170 & 215 & 213 \\
\hline CT30 & 315 & 135 & 1350 & 225 & 170 & 215 & 195 \\
\hline C0 & 100 & 0 & 0 & 25 & 170 & 215 & - \\
\hline CM10 & 90 & 10 & 0 & 25 & 170 & 215 & - \\
\hline CM20 & 80 & 20 & 0 & 25 & 170 & 215 & - \\
\hline CM30 & 70 & 30 & 0 & 25 & 170 & 215 & - \\
\hline
\end{tabular}

\subsection{Experimental Approach}

\subsubsection{Compressive Strength Test}

The compressive strength of the CMCT specimens was tested in accordance with the method specified in GB/ t1596-2017 "Fly Ash in Cement and Concrete" [24].

\subsubsection{X-CT Test}

The MicroXCT-400 X-ray 3D reconstruction scanning microscope (Carl Zeiss, Jena, Germany) was used for the X-CT test. For all samples, the X-ray tube voltage and current were $77 \mathrm{kV}$ and $129 \mathrm{~mA}$, respectively, during the text, and the pixel size was $1024 \times 1024$ with a resolution of $9.65 \mathrm{~m}$. The object rotation angle was $360^{\circ}$, and the exposure time for each projection was $5 \mathrm{~s}$. The hardened paste was taken after reaching the target age, the volume was broken to about $1 \mathrm{~cm}^{3}$, hydration was terminated by anhydrous ethanol, and it was vacuum dried at $60^{\circ} \mathrm{C}$ until a constant weight was reached.

\subsubsection{SEM Observation}

The Hitachi s-4800 (Hitachi, Tokyo, Japan) was used to conduct SEM analysis at an operating voltage of $10.0 \mathrm{kV}$. As with the X-CT test, the second electron image was used to observe the morphology of hydration products, and the amplification factor was 500 times.

\section{Results and Discussion}

\subsection{Compressive Strength}

Results from the compressive strength test of the CMCT with different curing ages are shown in Figure 3. The compressive strength of each CMCT increased with increasing curing age. With copper tailing content increase, when the curing age was less than $28 \mathrm{~d}$, the compressive strength of CMCT decreased; when the curing age was $28 \mathrm{~d}$, the compressive strength of CMCT with less than $10 \%$ copper tailing content was higher than that of ordinary cement mortar; when curing age was between $28 \mathrm{~d}$ and $180 \mathrm{~d}$ and copper tailing content was between $10 \%$ and $30 \%$, the compressive strength of CMCT increased sharply; when the curing age was $180 \mathrm{~d}$, the compressive strength of CMCT with less than $20 \%$ copper tailing content was close to that of ordinary cement mortar; when the curing age was between $180 \mathrm{~d}$ and $365 \mathrm{~d}$ and the copper tailing content was less than $30 \%$, the compressive strength of CMCT exceeded that of ordinary cement mortar. This is because the later hydration product of cement refined the pores of the mortar sample. In the sample, pore size was less than $30 \mu \mathrm{m}$, accounting for $80 \%$ of the total number of pores, and the particle size of less than $30 \mu \mathrm{m}$ of copper tailing accounted 
for $93.1 \%$ of the total, which was filled in the cement hydration hole, increased the compactness of cement mortar, and then increased the compressive strength of CMCT.

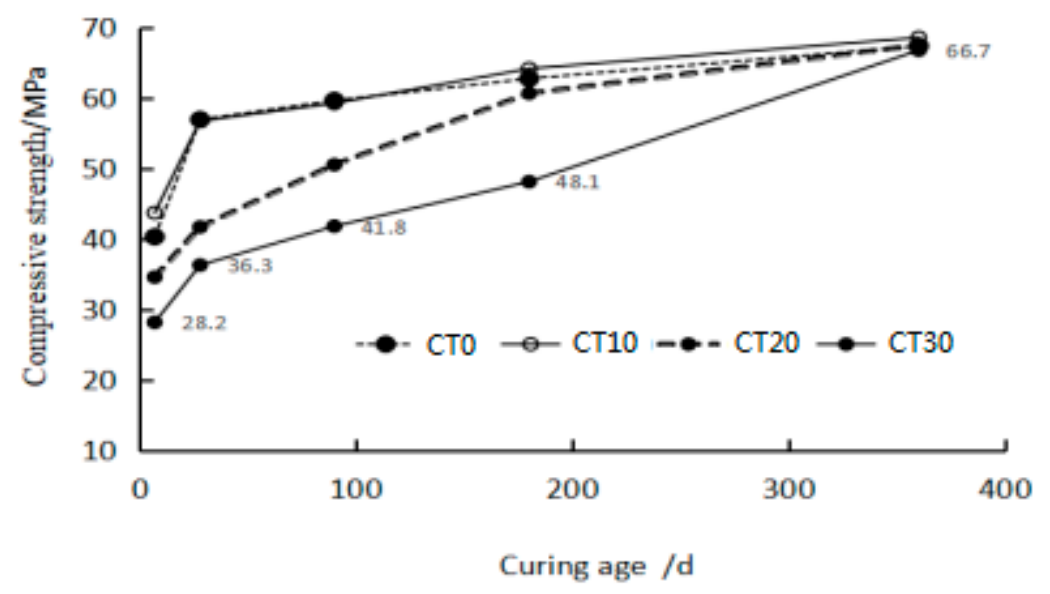

Figure 3. Compressive strength of cement mortar with copper tailing (CMCT) at different curing ages.

\subsection{X-CT Results}

Figure 4 shows the three-dimensional reconstruction of X-CT images of the CM30 samples after curing for $28 \mathrm{~d}, 180 \mathrm{~d}$, and $365 \mathrm{~d}$. The dark areas in the samples are all pores. As is evident, the number of large pores in the samples after curing for $180 \mathrm{~d}$ and $365 \mathrm{~d}$ decreased significantly, while the number of small holes increased. The pore volume distribution was more concentrated in the small holes, indicating that the extended curing time and cement hydration had a refining effect on the pore diameter in the CPCT.

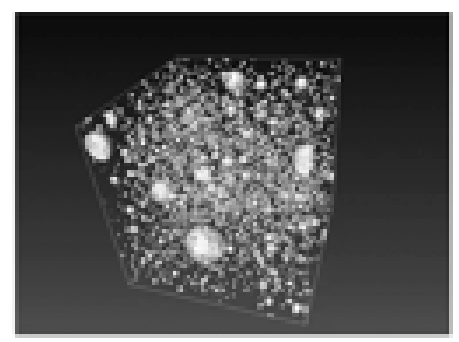

(a) $28 \mathrm{~d}$

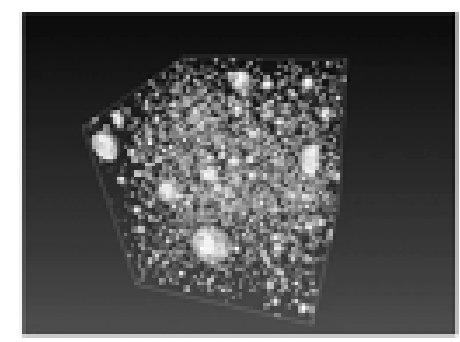

(b) $180 \mathrm{~d}$

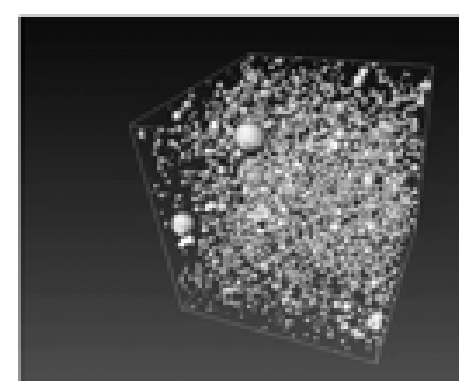

(c) $365 \mathrm{~d}$

Figure 4. X-CT images of the pores inside the CM30 samples. 


\subsection{MIP Results for Hole Structure}

\subsubsection{Porosity}

Figure 5 shows the effect of curing age on the porosity of the cement paste. With extended curing age, the porosity of the CPCT decreased. When the curing age was less than $180 \mathrm{~d}$, the porosity of the CPCT increased with increasing copper tailing content; on the other hand, when the curing age was more than $180 \mathrm{~d}$, the copper tailing content had little influence on the porosity of the CPCT.

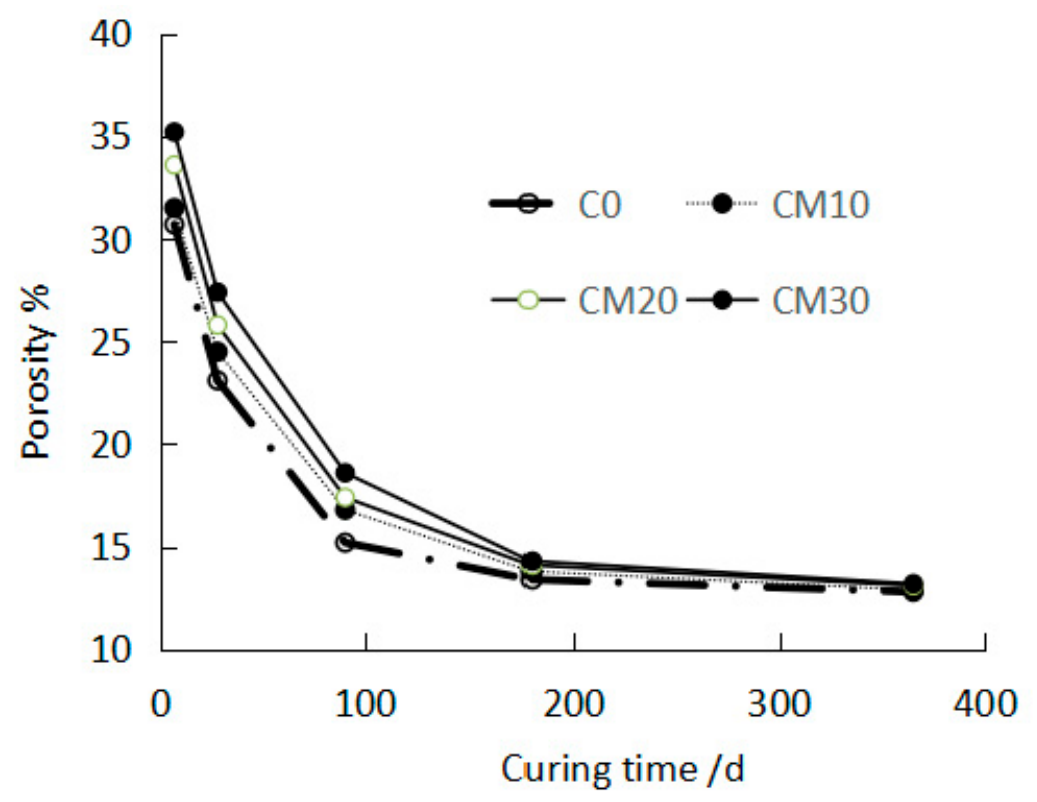

Figure 5. Effect of curing age of cement paste containing copper tailing (CPCT) on porosity.

\subsubsection{Maximum Aperture Distribution}

Figure 6 shows the pore size distribution of the hardened slurry with different copper tailing contents. The peak value on the curve is the maximum aperture. The maximum pore diameter of the cement slurry gradually decreased with increasing curing age; this was also observed for the CPCT. With increasing copper tailing content, when the curing age was $7 \mathrm{~d}$, the maximum pore size increased, whereas when the curing age exceeded $28 \mathrm{~d}$, the maximum pore size decreased. This is because of the many early cement hydration products [25], larger pore size [26], less copper tailing in the filling pores, and more capillary pores in СРCT. With prolonged aging, the maximum pore size of the CPCT was smaller than that of the pure cement sample. The results show that the pore size of the cement was decreased by the product of continuous hydration of cement, the capillary pores decreased due to filling by the copper tailing, and the pores of the cement filled with the copper tailing slag microaggregate were more compact. Even with prolonged aging, the above trend, i.e., smaller maximum pore diameter of the CPCT, existed. 


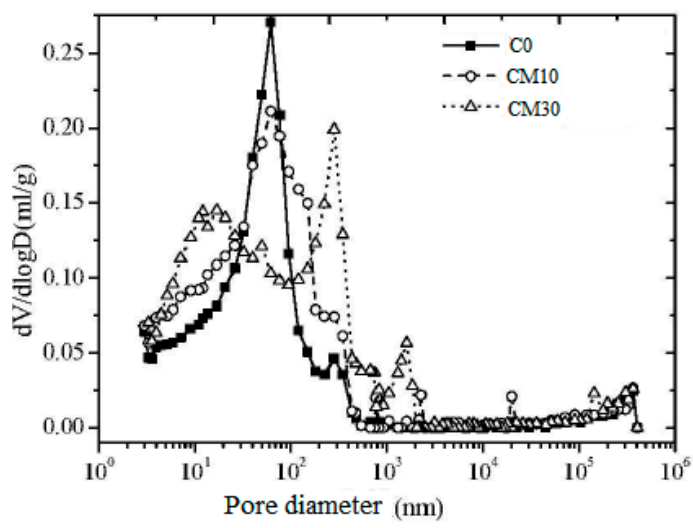

(a) $7 \mathrm{~d}$

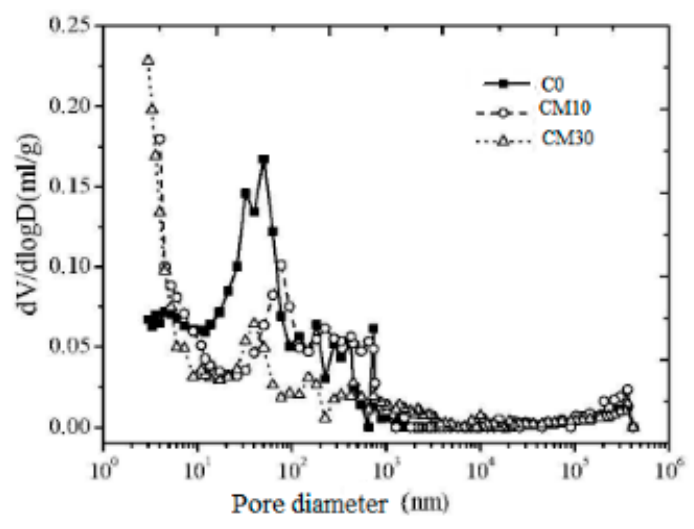

(c) $180 \mathrm{~d}$

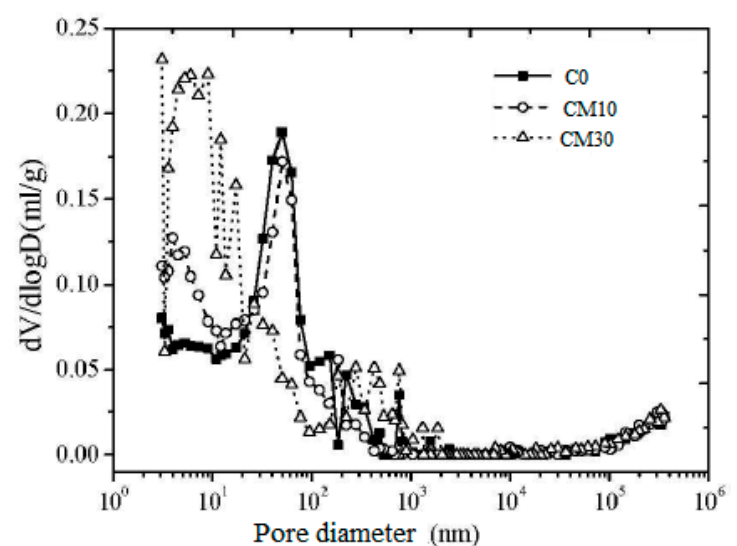

(b) $28 \mathrm{~d}$

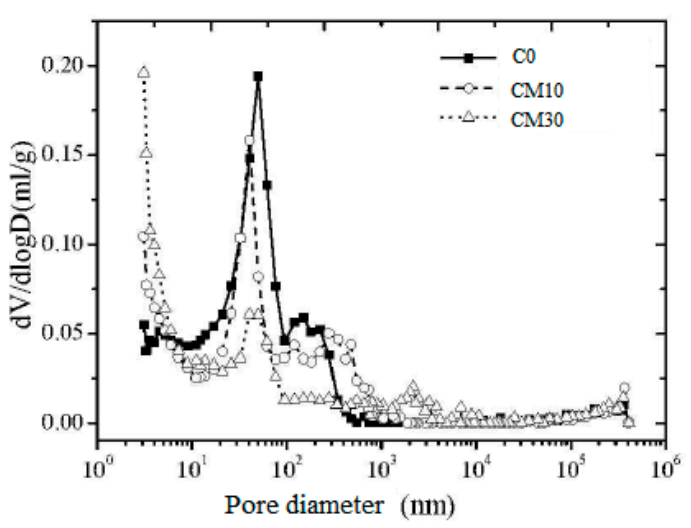

(d) $365 \mathrm{~d}$

Figure 6. Effect of copper tailing content on maximum pore size of CPCT.

\subsection{SEM}

The microstructures of the CPCT at different ages observed by SEM are shown in Figure 7. Figure $7 \mathrm{a}-\mathrm{c}$ show that, after curing for $7 \mathrm{~d}$ at room temperature, the hydration products of pure cement sample $\mathrm{C} 0$ were abundant, and were distributed on the surface of unhydrated particles. However, the CPCT structure was not dense enough, and the bond between the hydration products was not strong. For the CM10 and CM30 samples of CPCT, although some hydration products grew or covered the surface of unhydrated particles in the pores, the hydration products were not full and there were many pores. In particular, a large number of smooth rhomboid unhydrated copper tailing particles were observed in the CM30 sample with a high copper tailing content. This indicates that during curing at room temperature for $7 \mathrm{~d}$, the copper tailings did not fill the pores in the CPCT well. With the prolongation of the phase, the microstructure of each sample at $28 \mathrm{~d}$ and $180 \mathrm{~d}$ is shown in Figure $7 \mathrm{~d}-\mathrm{i}$. With the growth of the phase, the hydration products in each sample were abundant, the accumulation was dense, the CPCT structure was dense, and the pores were few. A large number of flaked $\mathrm{Ca}(\mathrm{OH})_{2}$ crystals were observed in samples with $10 \%$ and $30 \%$ copper tailing content, indicating that the copper tailing did not consume $\mathrm{Ca}(\mathrm{OH})_{2}$ and there was a large amount of $\mathrm{Ca}(\mathrm{OH})_{2}$ in the slurry. Figure 7j-1 show the microstructure of each sample at the long age. All samples of the CPCT were very dense, with abundant hydration products, and good filling pores. Even with the addition of copper tailing, it can be seen that the microaggregates of copper tailing had a good filling effect and closely combined with the surrounding hydration products. 


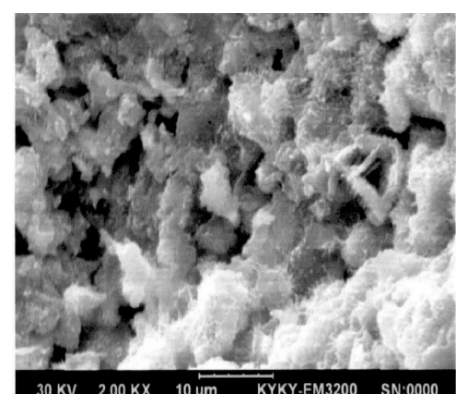

(a) $\mathrm{C} 0$

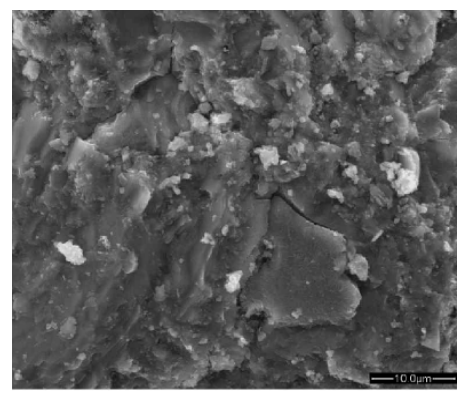

(d) $\mathrm{C} 0$

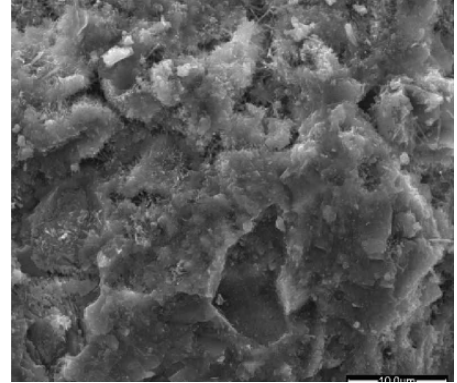

(g) $\mathrm{C} 0$

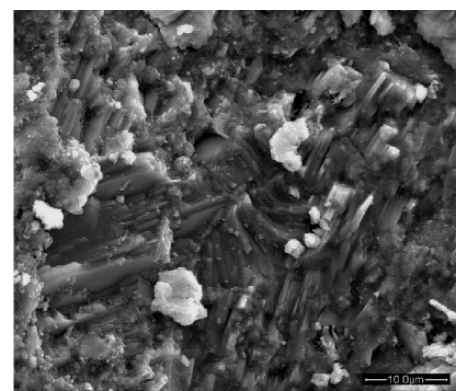

(j) $\mathrm{C} 0$

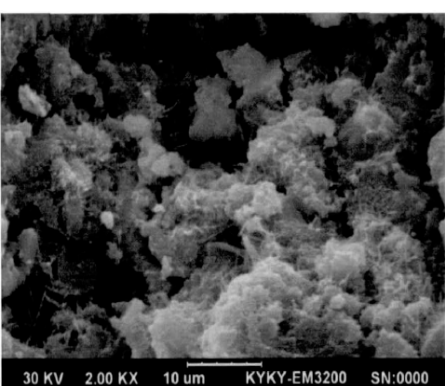

(b) CM10

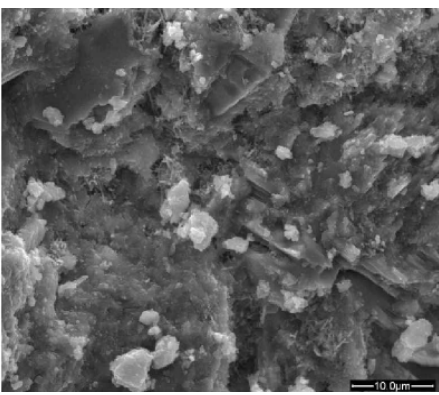

(e) $\mathrm{CM} 10$

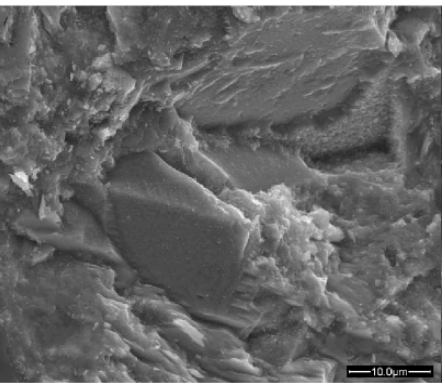

(h) $\mathrm{CM} 10$

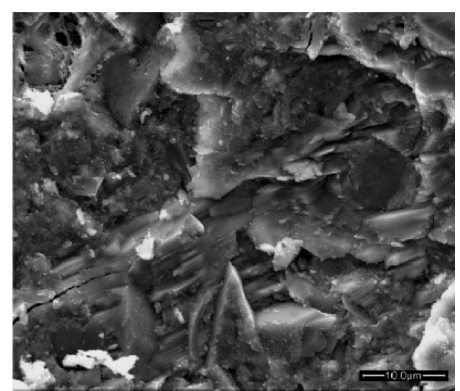

(k) CM10

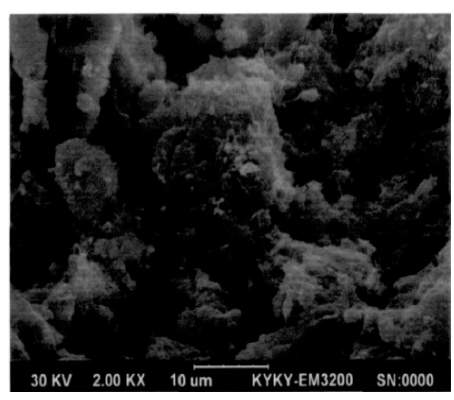

(c) $\mathrm{CM} 30$

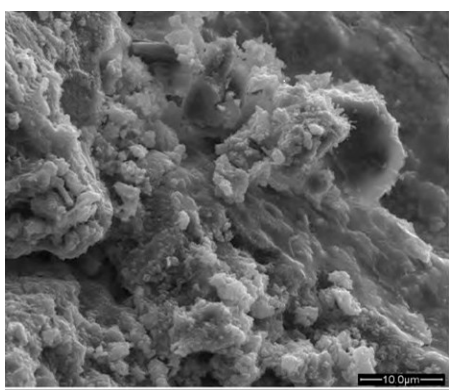

(f) CM30

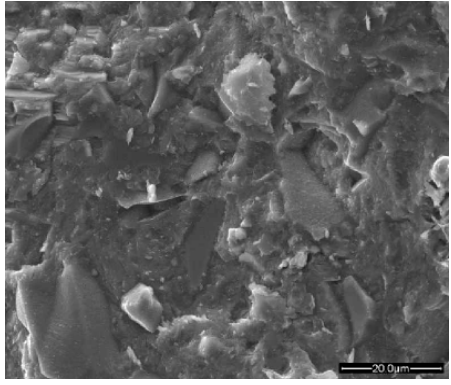

(i) CM30

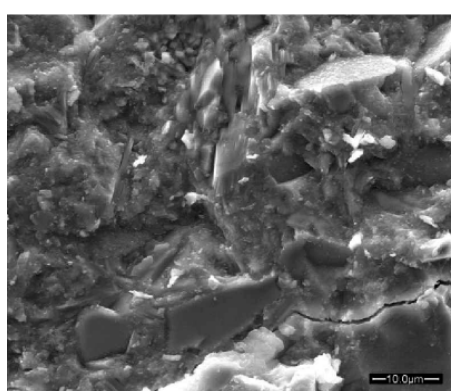

(I) $\mathrm{CM} 30$

Figure 7. SEM images of composite cementitious material at different curing ages. Curing for $7 \mathrm{~d}$ : (a) C0; (b) CM10; (c) CM30; Curing for $28 \mathrm{~d}$ : (d) C0; (e) CM10; (f) CM30; Curing for $180 \mathrm{~d}$ : (g) C0; (h) CM10; (i) CM30; Curing for 365 d: (j) C0; (k) CM10; (1) CM30. 


\section{Conclusions}

The compressive strength of CMCT and pore structure of CPCT cured to different ages were studied, and the following conclusions were obtained.

1. The compressive strength of CMCT increased with increasing curing age and was close to that of ordinary cement mortar with different curing time and copper tailing content. The curing time which the CMCT compressive strength was close to ordinary cement mortar compresssive increased with the increase of copper tailing content (less than $30 \%$ ). When the curing age was $365 \mathrm{~d}$, the copper tailing content was within $30 \%$, and further addition of tailing did not affect the compressive strength of concrete.

2. The porosity of the СРСТ decreased with increasing curing age and increased with the increase of copper tailing content when the curing age was less than $180 \mathrm{~d}$; the copper tailing content had little influence on the porosity of the CPCT when the curing age was more than $180 \mathrm{~d}$.

3. The maximum pore diameter of the CPCT gradually decreased with increasing curing age and increased with the increase of copper tailing content when the curing age was less than $7 \mathrm{~d}$; with curing time increases, the maximum pore diameter of the CPCT gradually decreased with the increase of copper tailing content. The $\mathrm{X}-\mathrm{CT}$ test results showed that prolonged curing and cement hydration played a role in refining the pore diameter of the CPCT.

4. In the early stage, the CPCT pore structure was less dense with copper tailing increases. With prolonged curing, the CPCT structure was gradually denser with copper tailing increases; the CPCT pore structure was denser with copper tailing increases until the curing age was more than $365 \mathrm{~d}$. The microaggregates of solid copper tailings had a good filling effect and closely combined with the surrounding hydration products.

Author Contributions: conceptualization, methodology, software, data curation, writing-original draft preparation, L.Z.; funding acquisition, project administration, writing-review and editing, investigation, resources, S.L.; validation, visualization, formal analysis, supervision, D.S.

Funding: This research was financially supported National Key Research and Development Plan “Solid Waste Resources" Key Projects (No.2018YFC1903402) and China Postdoctoral Science Foundation funded project (No. 2019M652280).

Acknowledgments: SEM experiments were done using facilities of the shared access center "Composition of compounds" (Institute of Electron microscopy center, School of materials science and engineering, Tsinghua university, Beijing, China); MIP:MPS was done using facilities of the shared access center "Material analysis and testing center" (School of materials science and chemical engineering, Ningbo university, Ningbo Zhejiang, China); C-XT was done using facilities of the shared access center "State key laboratory of high-performance civil engineering materials"(School of materials science and engineering, southeast university, Nanjing Jiangsu, China).

Conflicts of Interest: The authors declare no conflict of interest.

\section{References}

1. Cheng, W.M.; Nie, W.; Zhou, G.; Zuo, Q.M. Study of dust suppression by atomized water from high pressure sprays in mines. J. China Univ. Min. Technol. 2011, 40, 185-189.

2. Yu, L.H.; Jia, W.H.; Xuan, Y.Z. Survey and analysis of the Cooper tailing resources in China. J. Met. Mine 2009, 8, 179-181.

3. Li, H.G. Study on the Influence of Rain Fall Factors on Tailings Dam Break and Its Safety Warning Technology. Doctoral Thesis, University of Science and Technology Beijing, Beijing, China, 2017; pp. 179-181.

4. Seyed Rez, M.; Mostafa, F.; Ramin, T. Mechanical properties of concrete with Sarcheshmeh mineral complex copper slag as a part of cementitious materials. Constr. Build. Mater. 2017, 134, 44-49.

5. Onuaguluchi, O.; Eren, O. Copper tailings as a potential additive in concrete: Consistency, strength and toxic metal immobilization properties. Indian J. Eng. Mater. Sci. 2012, 19, 79-86.

6. Zheng, J.; Zhu, Y.; Zhao, Z. Utilization of limestone powder and water-reducing admixture in cemented paste backfill of coarse copper mine tailings. Constr. Build. Mater. 2016, 124, 31-36. [CrossRef] 
7. Kundu, S.; Aggarwal, A.; Mazumdar, S. Stabilization characteristics of copper mine tailings through its utilization as a partial substitute for cement in concrete: Preliminary investigations. Environ. Earth. Sci. 2016, 75, 226-235. [CrossRef]

8. Onuaguluchi, O.; Eren, O. Strength and durability properties of mortars containing copper tailings as a cement replacement material. Eur. J. Environ. Civ. Eng. 2013, 17, 19-31. [CrossRef]

9. Fang, Y.; Gu, Y.L.; Kang, Q.; Wen, Q.; Dai, P. Utilization of copper tailing for autoclaved sand-lime brick. Constr. Build. Mater. 2011, 25, 867-872. [CrossRef]

10. Yu, Z.R.; Gao, K.; An, M.Z. Influence of micro-structure on the strength and resistance to chloride ion permeability of reactive powder concrete. J. Xi'an Univ. Archit. Technol. 2013, 45, 31-37.

11. Poon, C.S.; Kou, S.C.; Lam, L. Compressive strength, chloride diffusivity and pore structure of high performance metakaolin and silica fume concrete. Constr. Build. Mater. 2006, 20, 858-865. [CrossRef]

12. Zhang, M.H.; Li, H. Pore structure and chloride permeability of concrete containing nano-particles for pavement. Constr. Build. Mater. 2011, 25, 608-616. [CrossRef]

13. Song, H.W.; Kwon, S.J. Evaluation of chloride penetration in high performance concrete using neural network algorithm and micro pore structure. Cem. Concr. Res. 2009, 39, 814-824. [CrossRef]

14. Zhao, X.L.; Wei, J.; Ba, H.J. Relationship between frost durability and pore structure of high performance concrete. Ind. Constr. 2003, 8, 5-7.

15. Liu, J.; Xing, F.; Dong, B.Q. Relationship between pore structure and permeability. Concrete 2007, $12,35-37$.

16. Zhang, P.; Qin, H.G.; Wu, K.S. Application of X-CT technology in the cement-based materials pore structure analysis. Ready-mixed Concr. 2011, 11, 27-29.

17. Han, J.; Pan, G.; Sun, W. Investigation on carbonation induced meso-defects changes of cement mortar using 3D X-ray computed tomography. J. Chin. Ceram. Soc. 2011, 39, 75-79.

18. Lu, S.E.; Landis, E.N.; Keane, D.T. X-ray micro-tomographic studies of pore structure and permeability in Portland cement concrete. Mater. Struct. 2006, 39, 611-620. [CrossRef]

19. Gao, P.W.; Lu, X.L.; Yang, C.X.; Li, X.Y.; Shi, N.N.; Jin, S.C. Micro-structure and pore structure of concrete mixed with superfine phosphorous slag and superplasticizer. Constr. Build. Mater. 2008, 22, 837-840. [CrossRef]

20. Li, H.; Xu, D.L.; Feng, S.H.; Shang, B.M. Micro-structure and performance of fly ash micro-beads in cementitious material system. Constr. Build. Mater. 2014, 52, 422-427. [CrossRef]

21. Duan, P.; Shui, Z.H.; Chen, W.; Shen, C. Effects of metakaolin, silica fume and slag on pore structure, interfacial transition zone and compressive strength of concrete. Constr. Build. Mater. 2013, 44, 1-6. [CrossRef]

22. Zhang, Z.Q.; Zhang, B.; Yan, P.L. Comparative study of effect of raw and densified silica fume in the paste, mortar and concrete. Constr. Build. Mater. 2016, 105, 82-93. [CrossRef]

23. Han, F.; Wang, Q.; Feng, J.J. The differences among the roles of ground fly ash in the paste, mortar and concrete. Constr. Build. Mater. 2015, 93, 172-179.

24. GB/T1596-2017. Fly Ash Used for Cement and Concrete; General Administration of Quality Supervision, Inspection and Quarantine of the People's Republic of China: Beijing, China, 2017; pp. 1-6.

25. Zhang, Y.; Yu, B. Characteristics of hydration products and pore structure in cement-based material with ultra fine slag at early ages. J. Southeast Univ. 2011, 41, 814-819.

26. Chen, $\mathrm{X}$.; $\mathrm{Wu}, \mathrm{S}$. Influence of water-to-cement ratio and curing period on pore structure of cement mortar. Constr. Build. Mater. 2013, 38, 804-812. [CrossRef]

(C) 2019 by the authors. Licensee MDPI, Basel, Switzerland. This article is an open access article distributed under the terms and conditions of the Creative Commons Attribution (CC BY) license (http://creativecommons.org/licenses/by/4.0/). 